\title{
MATHEMATISCH CENTRUM
}

2e BOERHAAVESTRAAT 49

AMSTERDAM

STATISTISCHE AFDELING

\author{
Leiding: Prof. Dr D. van Dantzig
}

Chef van de Statistische Consultatie: Prof. Dr J. Hemelrijk

\author{
SP 30 \\ Het uitzetten van waarnemingen op waarschijnlijkheidspapier \\ door \\ A.Benard en E.C.Bos-Levenbach
}


The plotting of observations on probability paper

The mathematical foundation of probability paper for a variate with ${ }^{-2}$ cumulative distribution function $F(x x+i)$ is explained as well as its purpose.

To plot the observations it is necessary to use an estimate of $F\left(x_{1}\right), x_{i}$ being the ${ }^{\text {th }}$ order statistic in the sample.

Several methods are described and compared, and a new one is developed, having the property that with a very good approximation the medians of $x_{i}$ are situated on a straight line. The derivations are given separately in an appendix. 
1. Inleiding.

Is $x$ een normaal verdeelde stochastische grootheid ${ }^{1}$ ) met gemiddelde $\mu$ en spreiding $\sigma$, waarvan

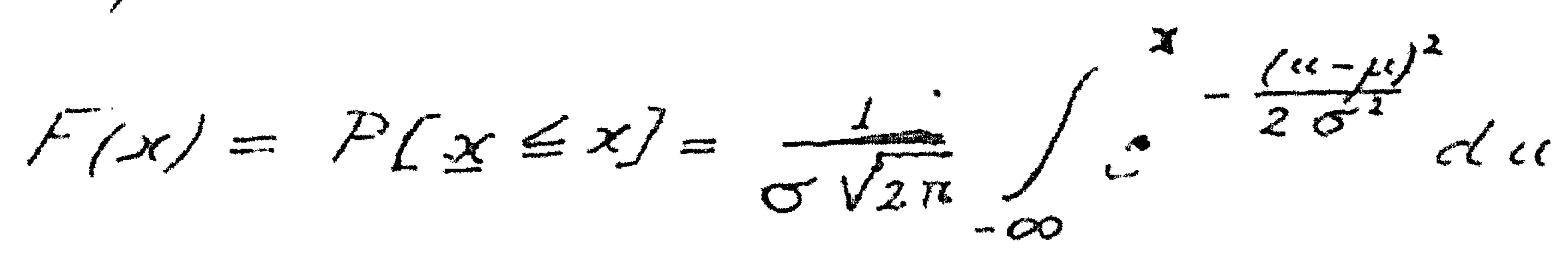

de verdelingsfunctie voorstelt, dan heeft de meetkundige plaats van de punten $\left(x, F^{\prime}(x)\right)$ op gewoon millimeterpapier uitgezet een gedaante als in figuur 1

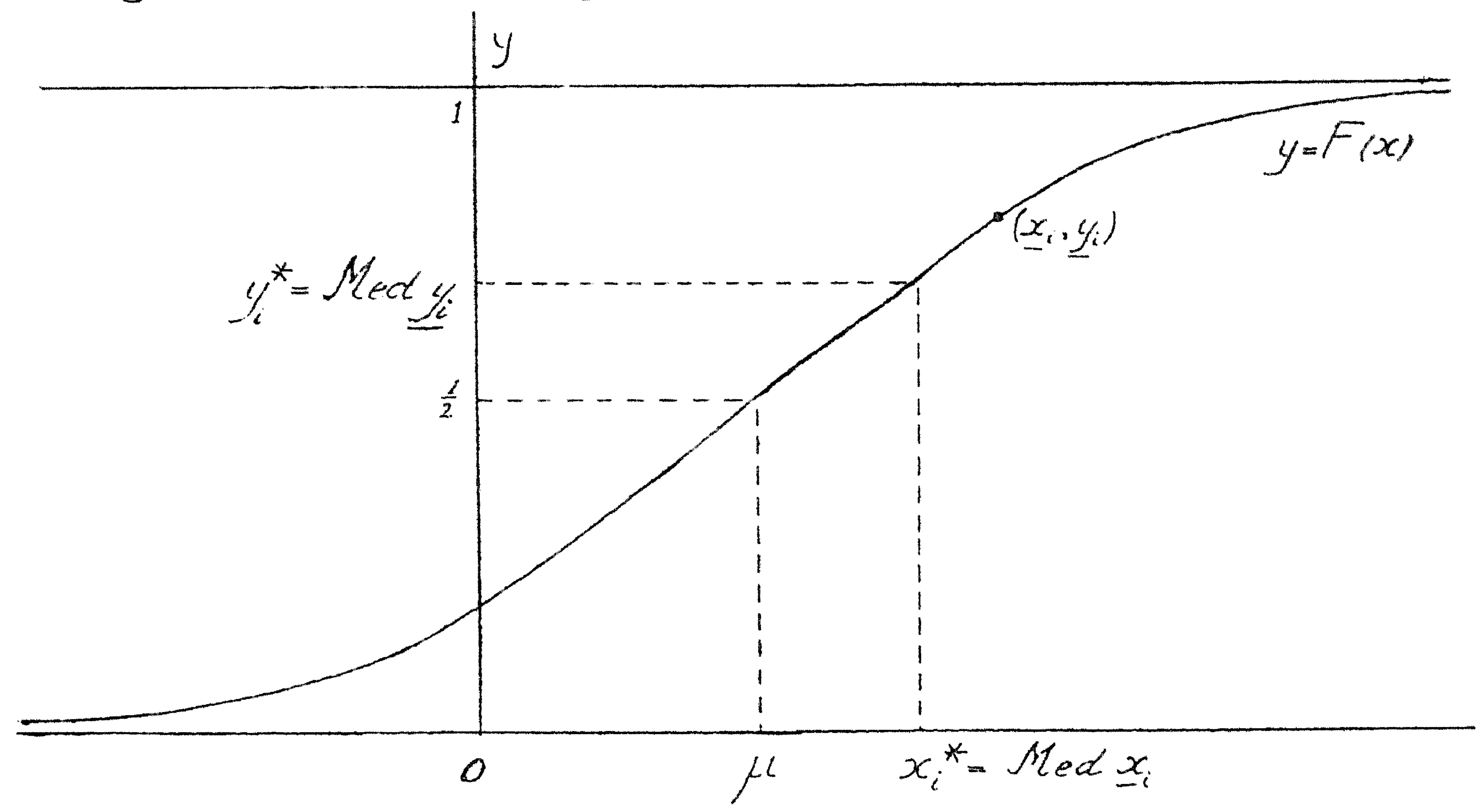

Fig. 1. Normale verdelingsfunctie op gewoon grafiekenpapier

Door transformatie van de verticale schaal kan men gedaar. krijgen, dat deze kromme lijn (voor ledere $\mu$ en $\sigma$ ) in een rechte Iijn overgaat. Deze transformatie bestaat daaruit, dat men op de verticale schaal bij het punt met ordinaat $y$ als nieuwe ordinate $\psi^{\prime}$ het getal $\Phi(y)$ zet, waarin $\Phi$ de verdelings-functie van de gestandaardiseerde normale verdeling voorstelt:

$$
\Phi(y)=\frac{1}{2 \pi} \int_{-\infty}^{y} e^{-\frac{u^{2}}{2}} d \ll
$$

Daar

$$
F(x)=P[x \leqslant x]=P\left[\frac{x-\mu}{\sigma} \leqslant \frac{x-\mu}{\sigma}\right]=\varnothing\left(\frac{x-\mu}{\sigma}\right)
$$

is, is de bij $y^{\prime}=F(x)$ behorende waarde van $y$ gelijk aan $\frac{x-\mu}{\sigma}$. De meetkundige plaats van de punten $\left(x, y^{\prime}\right)$ met $y^{\prime}=F(x)$ worat dus op de oorspronkelijke lineaire $y$-schal de meetkundige

1) Onderstreping geeft aan, dat de desbetreffende grootheid stochastisch is, d.w.z. een waarschijnlijkheidsverdeling bezit. 
plaats der punten $\left(x, \frac{x-\mu}{\sigma}\right)$, hetgeen een rechte lijn is. Hierbij is dan $\mu$ de abscis van het punt met ordinat $y^{\prime}=\frac{1}{2}$, terwijl $1 / \sigma$ de richtingscoëfficiënt van de lijn is.

Behalve dit normale waarschijnlijkheidspapier kan men op analoge wijze, uitgaande van een willekeurige verdelingsfunctie $F(x)$, waarschijnlijkheidspapier vervaardigen, waarop verdelings.. functies van het type $F(x x+\beta)$ (met $\alpha$ en $\beta$ parameters) door eer. rechte Iijn worden voorgesteld. Ook is het b.v. mogelifk waar. schijnlijkheidspapier te maken, behorende bij verdelingen van het type $F\left(e^{\alpha x+\beta}\right)$, door de ene schaal logarithmisch te trans.. formeren en de andere volgens $F(x)$. Hetzelfde geldt trouwens voor verdelingen van het type $F(\varphi(\alpha x+\beta))$, waarin $\varphi$ een willekeurige monotone functie is; de ene schaal wordt dan volgens $\varphi$ en de andere volgens $F$ getransformeerd.

De beschouwingen van de volgende paragrafen gelden alle voor leder van deze soorten warschijnlijkheidspapier.

2. Het doel van waarschijnlijkheidspapier.

Waarschijnlijkheidspapier kan o.a. gebruikt worden om op grond van een gegeven steekproef $x_{1}, \ldots, x_{n}$ op snelle wijze ee. schatting van de beide parameters $\mu$ en $\sigma$ te verkrijgen, $\ldots . .$. dien men de vorm der waarschijnlijkheidsverdeling van $x$ keni, of om een visuele indruk te krijgen ter beantwoording van de vraag, of deze grootheid $x$ een verdeling van het beschouwde type bezit.

In beide gevalien zal men de waarnemingen $x, \ldots, x_{n}$ op het waarschijnlijkheidspapier uit moeten zetten. Dit kan nu op verschillende manieren geschieden. De moeilijkheid zit daarin, det van ieder der punten $\left(x_{i}, F\left(x_{i}\right)\right)$, die op het waarschijnlijkhe1ds.. papier uitgezet precies op een rechte lijn zouden liggen, allee.. de coordinat $x_{i}$ bekend is, terwijl $F\left(x_{i}\right)$ onbekend is, daar $\mu$ en $\sigma$ niet bekend zijn. Men gebrulkt daarom in plaats van $F_{i} x_{i}$ zelf een schatting van $F\left(x_{i}\right)$ en hiervoor kan men verschillende functjes gebruiken.

3. Enkele gangoare methoden.

Wif zullen in het volgende onderstelien, dat de waarnemin. gen $x_{1}, \ldots, x_{n}$ genummerd $z i j n$ volgens opklimmende grootte, terwi... er geen gelijke waarnemingen zijn (bij een continue verdeling $\operatorname{van} x$ is de kans op gelijke waarnemingen gelijk aan 0 ), zodat wij dus hebben

$$
x_{1}<x_{2}<\cdots<x_{n}
$$


De verschiliende schattingen, die voor $F\left(x_{6}\right)$ gebrulkt worden, geven wij a an met $p_{,}(i), p_{2}$, , etc., daar zij alle alleen van het rangnummer i van de beschouwde warneming afhangen.

W1 J beschouwen eerst de veelal gebrulkellike functie

$$
\varphi_{i} 4=\frac{i}{n}
$$

Deze heeft het nadeel, dat $\varphi(n)=11 \mathrm{~s}$, zodat het punt $\left(x_{n}, \varphi,(n)\right)$ buiten het papier valt. Immers $y^{\prime}=1$ stat op de verticale schaal bij $y=\infty$, daar $\phi(\infty)=1$ is en dit punt bevindt zich dus nlet op het papier. Hetzelfde bezwar, maar nu voor $i=1$, geldt, indien men

gebruikt.

$$
\varphi_{2}(i)=\frac{i-1}{2}
$$

Dit bezwaar kan men op verschillende wijzen ondervangen, b.v. door de volgende functies te gebrulken of

$$
\varphi(2)=\frac{i-1}{n}
$$

$$
P_{4} / i=\frac{i}{n+\infty}
$$

Belde functies worden wel gebruikt en er zijn natuurlijk n. talloze andere mogelifkheden. Voor een keuze ult de verschillende mogelijkheden dienen de elgenschappen van deze verschillend. methoden onderzocht te worden. In alle gevalien zet men dus de punten

$$
\left(x_{1}, p(1), \ldots,\left(x_{n}, p(n)\right)\right.
$$

op het waarschijnlijkheidspapier uit en ult de vergelijkingen (4),... (7) valt te zien, dat de 4 boven beschreven methoden asymptotisch voor $n \rightarrow \infty$ aequivalent $z i j n$. Dit geldt ook voor de verderop nog in te voeren functies $y_{s}$ en $\varphi_{s}$.

4. De Ilgging van het punt ( $x_{i} \varphi(1)$.

Daar $\underline{x}_{i}$, de $i$ waarneming naar orde van grootte, een sto.. chastische grootheid is, geldt hetzelfde ook voor ledere functie van $x_{i}$ en dus in het bijzonder voor $F\left(x_{i}\right)$. Het punt $\left(x_{i}, F\left(x_{i}\right)\right.$ ligt voor ledere waarde van $x_{i}$ op de kromme $y=F(x)$ in figur 1, daar deze kromme de meetkundige plaats van deze punten is. Het stochastische punt $\left(x_{i}, F(x\right.$,$) heeft dus een warschijnlijk-$ heldsverdeling over deze kromme ${ }^{2}$ ). De stochastische grootheid

2) Deze waarschijnlijkheldsverdeling is niet dezelfde als de oprspronkelijke waarschijnlijkheldsverdeling van $x$, daar $x_{i}$ die $i^{*}$ waarneming bij rangschikking nar grootte voorstelt. 


$$
\underline{y}_{i}=F^{(x)} \quad(i=1, \ldots, i)
$$

bezit een warschijniljkheldsverdeling met als gemiddelde 3 )

en als modus

$$
e^{0}=\frac{i}{2+1}
$$

$$
\text { Aled } y=\frac{i-1}{12} \text {. }
$$

Verder geldt voor de mediaan $y^{*}$ van Y bij benadering:

$$
y^{*}=1 \text { Med } y \approx \frac{i-0,3}{12+0,4}
$$

en wly zlen, dat dit laatste getal steeds tussen de belde andere In IIgt. Men kan bewljzen, dat dit niet alleen voor deze benadering van de mediaan geldt, mar ook voor de mediaan zelf ${ }^{4}$ ).

Wij beschouwen nu warden van i> $\frac{n+l}{2}$ (voor waarden $<\frac{n+2}{2}$ gelden analoge conclusies). Voor een dergelijke i ge kut dus

$$
C_{y_{i}}<\operatorname{Mrd} y_{i}<\operatorname{Mod} \underline{y}_{i} \quad\left(i>\frac{2+1}{2}\right)
$$

Dit betekent, dat de bij $\underline{K}_{i}$ behorende waarde $\underline{Y}_{i}(z 1$ e (8)) vi boven dan onder zijn gemiddelde $\xi^{2} y_{i} 11$ gt, terwijl het omger... de voor de modus geldt. Daar het punt ( $\left.\underline{x}_{i}, y_{i}\right)$ steeds op de figuur 1 getekende kromme $11 \mathrm{gt}$, zal het punt ( $x_{i}, \frac{i}{n+1}$ ) in mea. dan de helft der gevalien onder deze kromme liggen en het pun

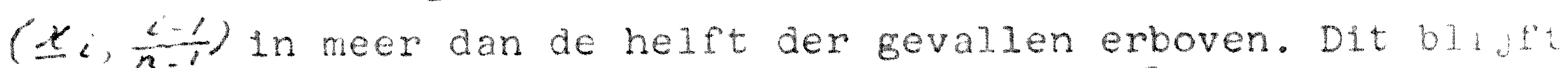
gelden, als men de verticale schaal volgens $\mathcal{f}(z l e(2))$ trons formeert, omdat deze transformatie monotoon is, d.w.z. de volf orde van de punten in verticale richting niet verandert.

De functie $\psi_{4}(z i e(7))$ heeft dus het bezwaar, dat voor i) $\frac{h+1}{2}$ de op het waarschijnlijkheidspapier ultgezette punten in meer dan de helft der gevalien onder de lijn liggen, d:e de onbekende waarschijnlijkheldsverdeling voorstelt, terwljl dit voor $i<\frac{n+1}{2}$ juist andersom is. Deze wijze van uitzetten hee"t dus tot gevolg, dat men in meer dan de helft der gevalien de lici. Iing van de lijn te laag. zal schatten, dus de spreiding te hoof. Daar komt nog bij, dat dit effect het sterkst is voor kleine cn voor grote waarden van $i$, waardoor de op deze wljze ultgezette punten de neiging hebben op het waarschijnlijkheidspapier min meer in een 5 -bocht te gaan 1iggen. Precles hetzelfde bezwaar,

3) Zie voor bewijzen en literatuurverwijzingen de appendix van dit artikel.

4) Het bewlys hiervan wordt in dit artikel nlet gegeven. Het volgt op eenvoudige wijze ult C.G.LEKKERKERKER [4] (zie ilteratuurlijst). 
maar nu juist andersom, geldt voor $\mathscr{P}_{3}$ (zie (6)), daar $\frac{i-1 / 2}{12}>\frac{i-0.3}{n+0.4} \quad$ voor $i>\frac{n+1}{2}$

en andersom voor $i \frac{12+1}{2}$. Deze wijze van uitzetten leidt dus tot een onderschatting van $\sigma$ in meer dan de helft der gevalien en eveneens tot 5 -bochten, maar nu in de andere richting.

Gebruikt men nu echter

$$
\varphi_{5} \text { (i) }=\frac{i-0,3}{n+0,4} \text {, }
$$

dan bestaan deze bezwaren niet, daar de punten $\left(x_{i}, \frac{i-0,3}{h+0,4}\right)_{\text {voor }}$ iedere $i$ ongeveer even vaak boven als onder de gezochte lijn zullen liggen.

Het bovenstaande wordt gelliustreerd door fig. 2. Daarin stelt de rechte lijn de verdelingsfunctic $y=F(x)$ voor (men moet de figuur dus op waarschijnlijkheidspapier getekend denken), $x_{i}^{*}$ stelt de medlaan van $\underline{x}_{i}$ en $y_{i}^{*}$ die van $\underline{y}_{i}$ voor. Het punt $\left(x_{i}{ }^{*}, y_{i}^{*}\right.$ ) ligt op de rechte $y=F(x)$ (zie ook opmerking 2 hieronder) en het punt $\left(\underline{x}_{i}, \underline{y}_{i}\right)$, dat een waarschijnlijkheidsverdeling op de lijn $y=F(x)$ bezit, ligt op deze lijn $\in$ ven vaak links als rechts van dit punt.

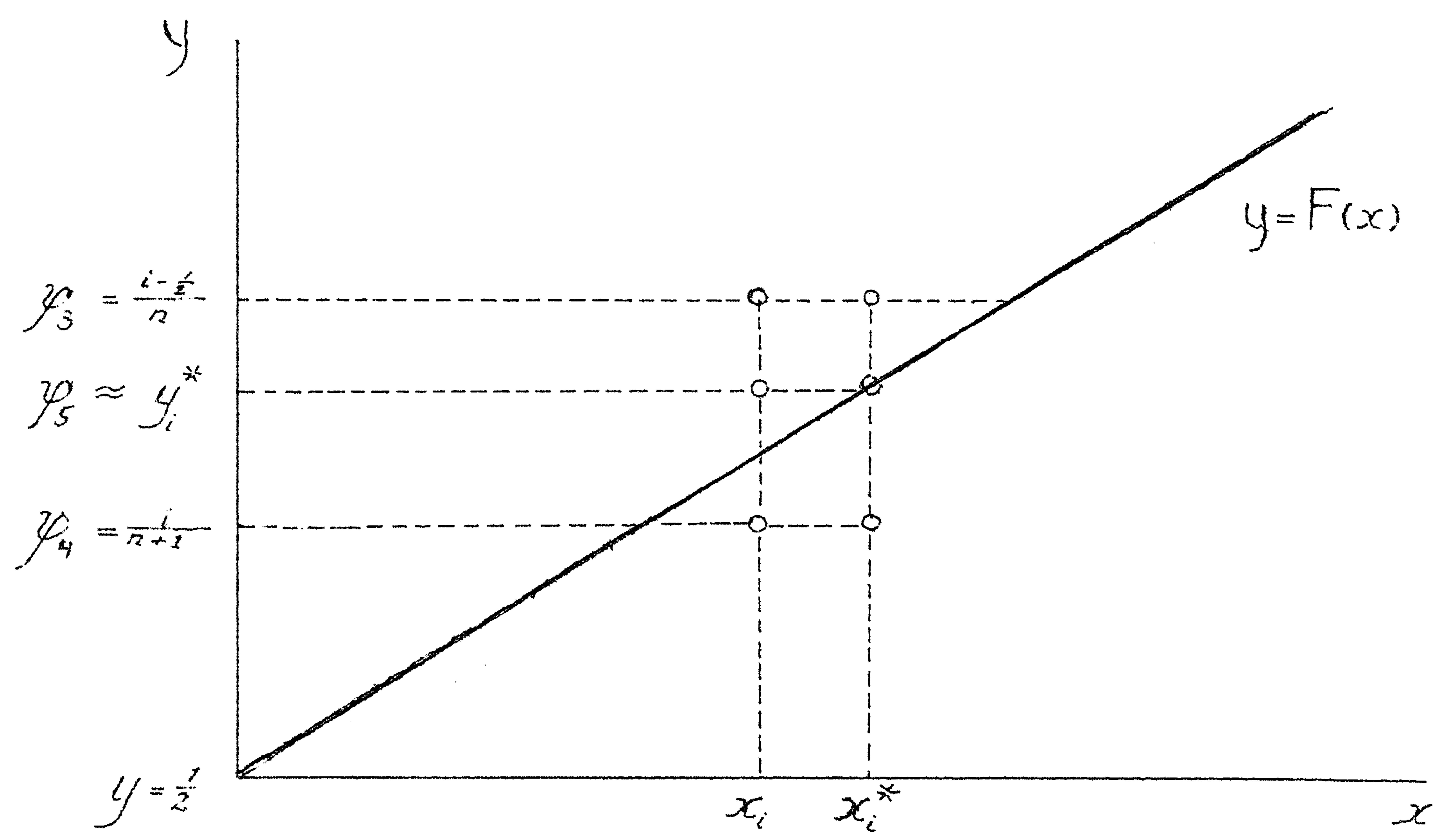

Fig. 2. Drie methoden voor het uitzetten van waarnemingen op waarschijnlijkheidspapier.

In de figuur ziet men, dat het punt ( $x_{i}, \mathscr{S}_{3}(i)$ ) even vacik links van $\left(\mathscr{K}_{i}^{*}, \mathscr{S}_{3}(i)\right.$ ) als rechts daarvan komt te liggen en cius vaker boven $y=F(x)$ dan daaronder ligt en omgekeerd voor $y_{4}(i)$. Het in de figuur getekende punt $x_{i}$ ligt links van $x_{i}^{*}$, terwijl toch $\left(x_{i}, \varphi_{i}(i)\right)$ nog onder de lijn ligt in plaats van erboven. 
opmerkingen.

1) Een zesde mogelijkheid

$$
C_{6} C L=\frac{i-1}{n-1}
$$

warin het rechterild dus de modus van $Y_{i}$ voorstelt, verenigt de bezwaren van $\mathscr{H}_{1}, \mathscr{Y}_{2}$ en $\mathscr{S}_{3}$ in zlch en kan dus niet aanbevolen worden.

2) Daar $Y_{i}$ een monotone functie ls van $x_{i}$ (1mmers $Y_{i}: F\left(x_{0}\right)$ vinden we een benadering voor de mediaan van 6 door de waarde $y_{i}=\frac{i-u_{3}}{n+0,4}$ te substitueren in de inverse functie $x_{i}=F^{-1}\left(y_{i}\right)$. Dus Med $x_{i} \approx F^{-1}\left(\frac{10}{n+0}\right) \cdot V g l \cdot f i g \cdot 1$.

3) Treden onder de waarnemingen door groepering of afronding gelijken op, dan kan men wellicht het beste de methode der gemiddelde rangnummers toepassen. Deze bestaat daarin, dat men alle waarnemingen uit een groep van gelijken als rangnummers het gemiddolde toekent van de rangnummers, die deze warnemin. gen gehad zouden hebben, indien zij ongelijk waren geweest, maar ten opzichte van alle niet tot die groep behorende waarnu... mingen dezelfde positie zouden hebben ingenomen bif rangschi... king naar grootte als nu het geval is. Deze gemiddelde rangni... mers vult men dan in de formules voor $\phi$ in.

4) De hier beschreven methoden putten natuurlijk de mogeIljkheden geenszins uit. E.J.GUMBEL [2] b.v. geeft voor het door hem ontworpen waarschijnlijkheidspapier voor de uiterste war. den (de dubbel-exponentielle verdeling) een methode aan, wacruij in verticale richting $F$ (mod $\underline{x}_{\text {. }}$ ) wordt uitgezet. Deze methode is voor het door hem beschouwde geval asymptotisch aequivalent met het gebruik van $\mu_{s}$, echter zonder het bezwaar, dat de eerste en de laatste waarneming niet uitgezet kunnen worden.

\section{Appendix.}

Geven wij de verdelingsfunctie van $y_{i}$ aan met $y_{i}$, dan geldt (zle b.V. D.van DANTZIG [1], hoofdstuk IV, par. 2):

$$
G_{i}(y)=\sum_{k=i}^{n}\left(\begin{array}{l}
n \\
k
\end{array}\right) y^{k}(1-y)^{n-k} \quad(0 \leq y \leq 1)
$$

hetgeen ook geschreven kan worden in de vorm

$$
G_{i}(y)=\frac{n !}{(i-i) !(n-i) !} \int_{0}^{y} u^{i-1}(1-u)^{n-i} d u \text {. }
$$

(zie b.v. M.G.KENDALL [3], p. 120). Door de tweede afgelelde van $G_{i}$ naar y gelijk aan nul te stelien, vindt men de modus var. $y_{i}$, dus (10). Ook de verwachting van $\underline{y}_{i},(9)$, volgt op de gebruikel1jke wijze ult (15). 
De exacte waarden van $y_{i}^{*}$, de mediaan van $y_{i}$, kan men vin.. den met behulp van tabelien van de onvolledige bêta-functie (b. $v$. C.M.THOMPSON [6]).

De benaderingsformule (11) leiden we als volgt af: voor iedere warde van de verdelingsfunctie $\mathscr{Y}$ geldt de volgende $b_{0 .}$ trekking:

$$
C_{i}(y)=\sum_{k=i}^{n}\left(\begin{array}{l}
n \\
k
\end{array}\right) y^{k}(1-y)^{n-k}=1-\sum_{k=0}^{i-1}\left(\begin{array}{l}
n \\
k
\end{array}\right) y^{k}(1-y)^{n-k}=1-\sum_{k=n-i+1}^{n}\left(\begin{array}{l}
n \\
k
\end{array}\right) y^{n-k}(1-y)^{k}=1-S_{n+1-i}(-y) .
$$

d.w.z. indien de waarnemingen niet naar opklimmende maar naar dalende grootte gerangschikt worden, dan wordt $i$ door $n+1-i, y$ door $1-y$ en $G$ door l-G vervangen. Het ligt voor de hand ook van $\varphi$ te verlangen dat a an deze symmetrierelatie voldaan is, d.w.z. dat geldt:

$$
\varphi(i)=1-\varphi(n+1-i) .
$$

Hieraan wordt door $\mathscr{C}$ en $\mathscr{C}_{2}$ niet voldaan, maar wel door de overige in het voorgaande genoemde functies $\varphi$.

Is nu $\mathscr{Y}_{i}{ }^{*}$ de mediaan van $\mathscr{Y}_{i}$, zodat

$$
G_{i}\left(Y_{i}^{*}\right)=Y_{2} \text {, }
$$

dan is dus

$$
1-G_{n+1-i}\left(1-y_{i}^{*}\right)=1 / 2
$$

dus $1-y_{i}^{*}$ is de medjaan van $y_{n+1-i}{ }^{5}$ ). Wij schrijven $y_{i}^{*}$ nu als

$$
y_{i}^{*}=\frac{i-a}{n+b}
$$

Uit (16) en (17) volgt de relatie

$$
-\frac{i-a}{n+b}=\frac{n+1-i-a}{n+b}
$$

en hieruit volgt

$$
B=1-2 a
$$

Formule (17) gaat hierdoor over in

$$
y_{i}^{*}=\frac{i-a}{n+1-2 a}
$$

terwijl a nog zou moeten voldoen aan de betrekking

$$
\sum_{n=i}^{n}\left(\begin{array}{l}
n \\
k
\end{array}\right)\left(\frac{i-a}{n+1-2 a}\right)^{k}\left(1-\frac{i-a}{n+1-2 a}\right)^{n-k}=1 / 2 \text {, }
$$

waarvoor wij ook kunnen schrijven

$$
\sum_{k=0}^{i}\left(\frac{i-a}{n+1-2 a}\right)^{k}\left(1-\frac{i-a}{n+1-2 a}\right)^{n-k}=1 / 2 \text {. }
$$

5) Asymptotisch voor $n \rightarrow \infty$ geldt $y_{i}{ }^{*}=\frac{\dot{L}}{n}$. 
De $a$, die aan deze betrekking voldoet, kan weer gevonden worden met behulp van tabelien van de onvolledige bêta-functius en deze $a$ hangt uiteraard zowel van $i$ als van $n$ af. Wij zoeken nu een constante als benadering voor $a$, die voor iedere i en $r$ voldoende nauwkeurig is voor practisch gebruik en nemen dad... toe in het linkerlid de limiet voor $\rightarrow \infty$ :

$$
\begin{aligned}
& \lim _{n \rightarrow \infty} \sum_{k=0}^{i-1} \frac{n !}{(n-k) ! k !} \frac{(i-a)^{k}}{(n+1-2 a)^{k}}\left(1-\frac{i-a}{n+1-2 a}\right)^{n-k}= \\
& \lim _{n \rightarrow \infty} \sum_{k=0}^{n} \frac{n(k-1) \cdots(n-k+1)}{(n+1-2 a)^{k}} \frac{(i-a)^{k}}{k !} e^{-(i-a)}= \\
& e^{-(i-a)} \sum_{k=0}^{i-1} \frac{(i-a)^{k}}{k !} .
\end{aligned}
$$

Deze limiet stelien wij nu gelijk aan $\frac{1}{2}$.

Dit betekent dus, dat wij een Poisson-verdeling zoeken, met gemiddelde $i$-a en mediaan $i$. Voor iedere waarde van $i$ kunnen wij nu, met behulp van een tabel van Poisson-verdelingen (b. $v$. E.C.MOLINA [5]) de bijbehorende waarden van a bepalen. Het ro... sultaat hiervan vindt men in tabel $I$.

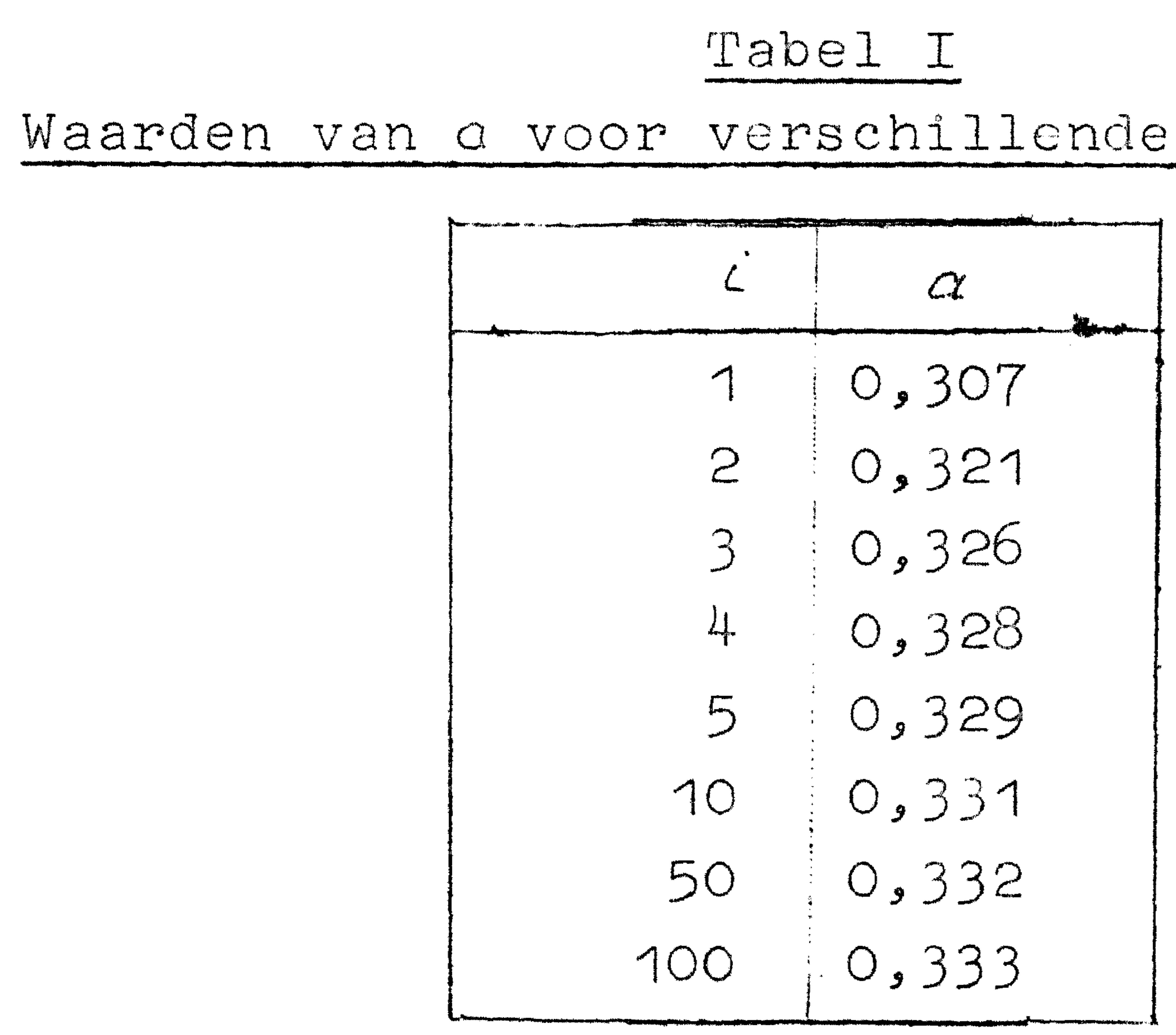

Daar wij één vaste waarde voor a willen gebruiken en daar voor $i=1$ en $i=n$ de bijbehorende puncen $\left(x_{i}, \varphi(i)\right.$ ) gewoonlijk de grootste afwijkingen van de reahte lijn vertonen, kiezen we de daarbij behorende waarde van $a$, die wij voor het gemak op 0,3 afronden.

Om de invloed van de boven gebruikte limietovergang voor $n \rightarrow \infty$ na te gaan, hebben wij voor $i=t$ en voor enkele kleine waarden van $n$ de exact warde van $\oint_{1}\left(\frac{1-a}{n+1-2 a}\right)$ met $a=0,3$ bepaala, die dus, als a precies juist was, gelijk a an zou moeten zijn. 
De resultaten, samengevat in tabel II, zijn gunstig.

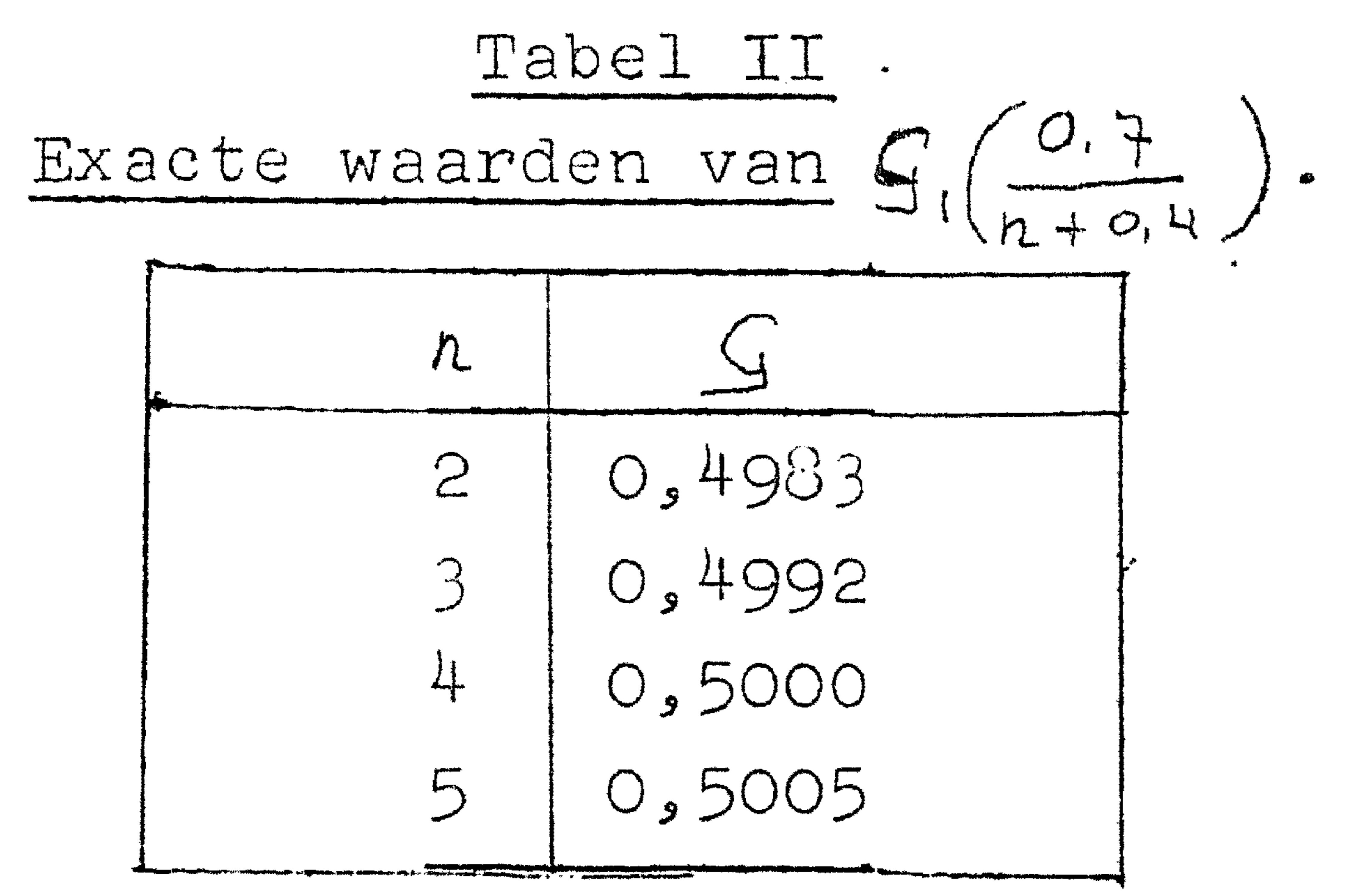

Ten slotte hebben wij, voor $n=10$ en $n=15$, de waarden vergeleken met de exacte medianen, die uit de tabel [5] bepaald kunnen worden en bij gebruik warvan voor iedere $i$ de kans, dat het punt ( $\underline{x}_{i}, \underline{f}(i)$ ) boven de rechte lijn komt te liggen, precies gelijk aan $\frac{1}{2}$ zou zijn (maar die niet door een constante a weergegeven kunnen worden). Deze waarden bleken vrijwel steeds tot in drie decimalen overeen te stemmen, terwijl het verschil voor geen enkele $i$ meer dan $1 \%$ bedroeg. Hieruit kunnen wij dus concluderen, dat de benadering voor practische doeleinden ruim voldoende is en dat men door de punten ( $x_{2}, \frac{i-0}{n}$ ) op waarschijnlijkheidspapier uit te zetten bereikt, dat ieder der punten gelijke kans bejit om boven of onder de gezochte lijn te komen liggen.

Literatuur.

[1] D.van DANTZIG, Kadercursus Mathematische Statistiek, Mathematisch Centrum, Amsterdam 1947.

[2] E.J.GUNBEI, The return period of flood flows, Annals of No.. thematical statistics 12 (1941), p. 163..190.

[3] M.G.KENDALI, The advanced theory of statistics, Vol. I, London 1947.

[4] C.G.LEKKERKERKER, Rapport Z.W.1953..016, AfdeIing Zuivere Wiskunde, Mathematisch Centrum, Amsterdan.

[5] E.C.MOLINA, Poisson's exponential binomial Iimit, D.van Nostrand, Comp.s Inc., N.Y. 1945.

[6] C.M.THOMPSON, Tables of percentage points of the incomplete bêta-function, Biometrika 32 (1941), p. 163181. 